We must not see CPD as an imposition

from a tiresome 'they' who say we have

to do it, but as a genuine opportunity to

fulfil our own goals for learning, self

improvement and development for

ourselves and our practices

\section{CPD revisited}

The publication of the paper in the previous issue of the $B D J^{1}$ on the use that readers make of our CPD programme, which we offer in conjunction with Eastman CPD, coincided in my post with the arrival of a letter from the General Dental Council (GDC).

It was one of those odd coincidences that spur a thought which might not otherwise have crystallised. As you will no doubt be aware, the annual retention fee reminder came with a covering letter from President Hew Matheson and an advice sheet about Dental Care Professionals (DCPs). This consisted of information reminding dentists, as employers, about their responsibilities from next year onwards in respect of those DCPs, who from July 2006 will be required to register with the GDC. What the letter didn't specifically point out but which is implicit in the process of registration and 'professionalisation' is that the DCP groups; dental nurses, dental technicians, clinical dental technicians and orthodontic therapists, will also be required in due course, to undertake CPD. This is under the same lifelong learning philosophy that applies to us as dentists and many other professional groups.

There are several points of interest in the $B D J$ paper in respect of the way in which readers currently use and regard our CPD programme. Incidentally, the paper was written and accepted sometime ago (the delay in such things is another matter that we have plans to solve next year, but more of that anon) so that although it referred to 7,200 registered users, the number now hovers tantalisingly close to 8,000 , which as far as we know is the largest single CPD programme in the UK.

The majority used the programme in conjunction with other forms of CPD, notably lectures and courses. Likewise, the majority also claimed that they had changed some aspect of their clinical practice as a result of using the programme. These are both encouraging results. As I have written here before, we must not see CPD as an imposition from a tiresome 'they' who say we have to do it, but as a genuine opportunity to fulfil our own goals for learning, self improvement and development for ourselves and our practices.

Which brings me back to the GDC's advice on our duties as employers and leaders of the dental team, for not only in the future will we need to consider our own CPD but, sensibly, will need to take into account the requirements of our newly registered team members. I am pleased to report that BDA publications are already putting plans into place for this eventuality as part of the overall scheme of things. In the same way that $B D J$ readers use the journal CPD programme as one element of their overall personal plans, we calculate that so too in the future will the newly registered team members use journal CPD as part of theirs. However, this also throws up the possibility of team CPD and the very real advantage of genuine team involvement in further education and training not only for the benefit of the individuals but also for practices, clinics and departments and by its very nature, patient care.

In the same way that it has taken, and continues to take, time for the realisation of how valuable CPD can be, rather than another unwelcome extra burden, so too will it take time for the concept of team co-ordinated CPD to gain ground. But that's fine. Better that these elements develop gradually and expand with the usual measure of pragmatism that marks out our profession, than that we are too prescriptive of them from the beginning.

There is no doubt that the coincidence of DCP registration and CPD commitment will create many exciting opportunities to enhance the art and science of dentistry as well as the importance and progression of patient care. What is more exciting still is that 2005 will be the last year in which it will not happen.

1. Tredwin CJ, Eder A, Moles DR and Faigenblum. British Dental Journal based Continuing Professional Development: A survey of participating dentists and their views. Br Dent J 2005; 199: 665-669.

Stephen Hancocks OBE, Editor in Chief doi: 10.1038/sj.bdj.4812989 